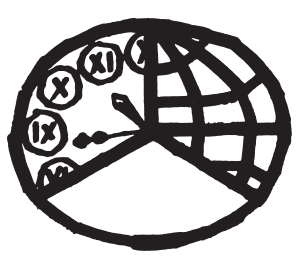

\title{
PINARES Y ENEBRALES. EL PAISAJE SOLUTRENSE EN IBERIA
}

\author{
Pine and juniper forest. Solutrean landscape in Iberia
}

\author{
Ernestina Badal ${ }^{1}$, Yolanda Carrión ${ }^{1}$, Isabel Figueiral ${ }^{2}$ y María Oliva Rodríguez-Ariza ${ }^{3}$
}

Recibido el 15 de marzo de 2013. Aceptado el 12 de septiembre de 2013

\begin{abstract}
Resumen. Se presentan estudios antracológicos de yacimientos de la península Ibérica con el objetivo de conocer la flora durante el Solutrense y, a partir de ella, las condiciones termoclimáticas y ombroclimáticas. Con los datos publicados e inéditos se demuestra que los refugios de las especies más cálidas están al sur del paralelo $40^{\circ} \mathrm{N}$. La flora identificada en los carbones se puede agrupar en cuatro categorías: criófilas, termófilas, matorral y ribera. Se observa un gradiente latitudinal de la distribución de los marcadores más térmicos como Pinus pinea, Rosmarinus officinalis, mientras que los pinos criófilos están distribuido por todas las regiones. Se propone la identificación botánica de los carbones antes de hacer una datación radiométrica sobre ellos y publicar dicha identificación junto a la fecha radiocarbono para conocer la historia de las plantas y su distribución peninsular.
\end{abstract}

Palabras clave: carbón, Solutrense, AMS, vegetación, refugios.

Abstract. Data obtained by charcoal analysis from Iberian sites are presented in order to improve our knowledge of the Solutrean flora and consequently of the climatic and edaphic conditions. Published and unpublished data suggest that refuge areas for thermophilous plants are located south of parallel $40^{\circ} \mathrm{N}$. Plants identified via the identification of charcoal may be divided into four categories representing: temperate / cold conditions, warm / dry conditions, matorral and riverine habitats. A latitudinal gradient is recognized concerning the distribution of species associated with warmer conditions, such as Pinus pinea and Rosmarinus officinalis, while cryophilous pines are present everywhere. Charcoal identification previous to $14 \mathrm{C}$ dating should become a standard practice, making it possible to trace the history of plants and their distribution throughout Iberia.

Keywords: charcoal, Solutrean, AMS, vegetation, refuges.

\section{INTRODUCCIÓN}

El Último Máximo Glacial (UMG o LGM) supone uno de los periodos con clima más frío del Planeta. No obstante, en las condiciones climáticas y, en especial, en la distribución de la temperatura, influye de manera notoria la latitud y la altitud, creando los grandes cinturones climáticos de la Tierra. Las latitudes altas concentraron los grandes casquetes glaciares lo que precipitó el descenso latitudinal y altitudinal de los climas fríos y templados (Frenzel et al. 1992; Lowe y Walker 1997) y con ellos las faunas y floras frías se expandieron hacia el sur. Las tres penínsulas mediterráneas (Ibérica, Itálica, Balcanes) se han postulado como zonas refugio de las especies templadas y cálidas a partir de datos polínicos y faunisticos (Willis y van Andel 2004). Recientemente, los análisis antracológicos se han unido a esta problemática (Badal et al. 2012; Carrión et al. 2010; González et al. 2010; Ntinou 2002) corroborando estos resultados.

(1) Dpto. de Prehistoria y Arqueología. Facultad de Geografía e Historia. Universidad de Valencia. Av. Blasco Ibáñez, 28. E-46010 Valencia (España).ernestina.badal@uv.es·yolanda.carrion@uv.es

(2) IINRAP Méditerranée, CBAE, UM2 / CNRS / EPHE. Montpellier (France). isabel.figueiral-rowe@inrap.fr

(3) IInstituto Universitario de Arqueologia Ibérica. Universidad de Jaén. Campus Las Lagunillas. E-23071 Jaén (España).moliva@ujaen.es 
El presente artículo se basa en el análisis de los carbones procedentes de varios yacimientos arqueológicos ibéricos con registros solutrenses y un yacimiento natural (Cortegaça - playa) donde se han conservado tocones de madera en posición de vida, datados en la misma franja cronológica. Presentaremos una síntesis de los datos disponibles a fin de:

a) conocer la flora leñosa durante el Solutrense $y_{1} a$ partir de ella, las condiciones termoclimáticas y ombroclimáticas, ya que el carbón puede identificarse a menudo en el rango de género y especie vegetal.

b) evidenciar que las formaciones vegetales más frecuentes en la lberia solutrense son pinares criófilos, enebrales - sabinares y matorrales diversos.

c) demostrar que las especies vegetales cálidas se refugiaron en el sur de lberia. El carbón procede de las especies leñosas recolectadas y usadas directamente por los propios solutrenses de modo que, al proceder del territorio inmediato a los yacimientos, ofrece una información de la flora local.

d) concienciar a los arqueólogos que no debe fecharse por radiocarbono ningún carbón sin su previa identificación botánica. Con cada fragmento de carbón podemos obtener dos tipos de información: primero la botánica (por medio de la anatomía vegetal) y después la cronológica (por medio del radiocarbono).

Los datos antracológicos son, todavía, muy pocos para reconstruir, de forma exhaustiva, los paisajes vegetales durante el Solutrenses en Iberia, así que intentaremos dar una visión general de las formaciones leñosas más expandidas durante el Último Máximo Glacial aunque con grandes lagunas cronológicas y espaciales que se pueden correlacionar con el poblamiento solutrense de la península lbérica (Banks et al. 2009).

\section{MÉTODOS Y MATERIALES}

En la Fig. 1 se representan los yacimientos que se tomarán en consideración, en el contexto bioclimático actual. Todos son antrópicos salvo Cortegaça - playa. Algunos de ellos ya se han publicados y otros están completamente inéditos. Ninguno de ellos registra todo el periodo, muchos sólo tienen un nivel de algunas de las fases del Solutrense y la cantidad de material es dispar, desde muy escaso hasta francamente abundante (Tabs. 1 y 2). Por tanto, la información es desigual en lo cronológico, espacial y botánico pero muy valiosa por ser una información directa sobre las condiciones ecológicas y la etnobotánica disponible para este periodo. Además, los carbones proceden de la reco- lección de leña local, por tanto, es un documento directo de los paisajes de cada yacimiento durante el Solutrense. Evidentemente, hay un filtro humano en la recogida de leña y es muy probable que hubiera en el entorno más plantas leñosas de las que identificamos, de igual modo que había más especies de fauna que las identificadas en los restos óseos, pero los conjuntos (flora y fauna) son coherentes desde el punto de vista ecológico, por tanto, nos permiten aproximarnos al paisaje del Solutrense. Hemos tomado en consideración los yacimientos que tienen niveles solutrenses, en sentido muy amplio, desde lo que algunos autores Ilaman Proto-Solutrense hasta Solutreo-Gravetiense o incluso Badeguliense, lo que en cronología sin calibrar iría desde aproximadamente 21500 a 16500 BP (Tabs. 1 y 2). Los yacimientos se encuentran desde prácticamente el nivel del mar hasta los $1000 \mathrm{~m}$ de altitud, aunque la mayoría de ellos está por debajo de los $500 \mathrm{~m}$. En las tablas 1 y 2 se presentan los yacimientos de norte a sur porque la latitud, junto a la altitud, son parámetros importantes para las condiciones térmicas $y$, en consecuencia, para la distribución de los vegetales, tanto ahora como en el pasado. En la actualidad, están en los pisos bioclimáticos más cálidos de la región Mediterránea, es decir, en el termomediterráneo y el mesomediterráneo, salvo la Cueva de Ambrosio, que está en el límite con el supramediterráneo. Los de la región Eurosiberiana están en el piso colino que es el más cálido de esta región (Fig. 1).

En los yacimientos arqueológicos, los métodos de muestro del carbón pueden variar y no siempre se indica en las publicaciones, pero normalmente se recuperan por medio del tamizado en seco o el flotado de los sedimentos arqueológicos, siguiendo los criterios estratigráficos de cada yacimiento. En la Cova de les Cendres y en Santa Maira se han utilizado los dos métodos y no hemos encontrado diferencias significativas entre ellos. La recogida a mano durante el proceso de excavación sólo se debe realizar en aquellos carbones geo-referenciados que se quieran datar por radiocarbono y, evidentemente, se datarán después de la identificación botánica.

Todos los carbones recogidos en una unidad estratigráfica conforman la muestra antracológica, donde el fragmento de carbón es la unidad de identificación y recuento, sin tener en cuenta su tamaño (Chabal 1997). La identificación botánica del tejido vegetal carbonizado se realiza en un microscopio óptico de luz reflejada con campo claro - campo oscuro. En ese proceso, la preparación de las muestras es puramente mecánica, es decir, el material se parte con las manos sin utilizar ningún tipo de tratamiento químico, lo cual permite con posterioridad utilizar técnicas de radiocarbono sobre el mismo resto orgánico (Vernet et al. 1979). En el caso de la madera se realizan láminas delgadas y se identifica en el microscopio de luz transmitida (Schweingruber 1990). En la mayoría de 


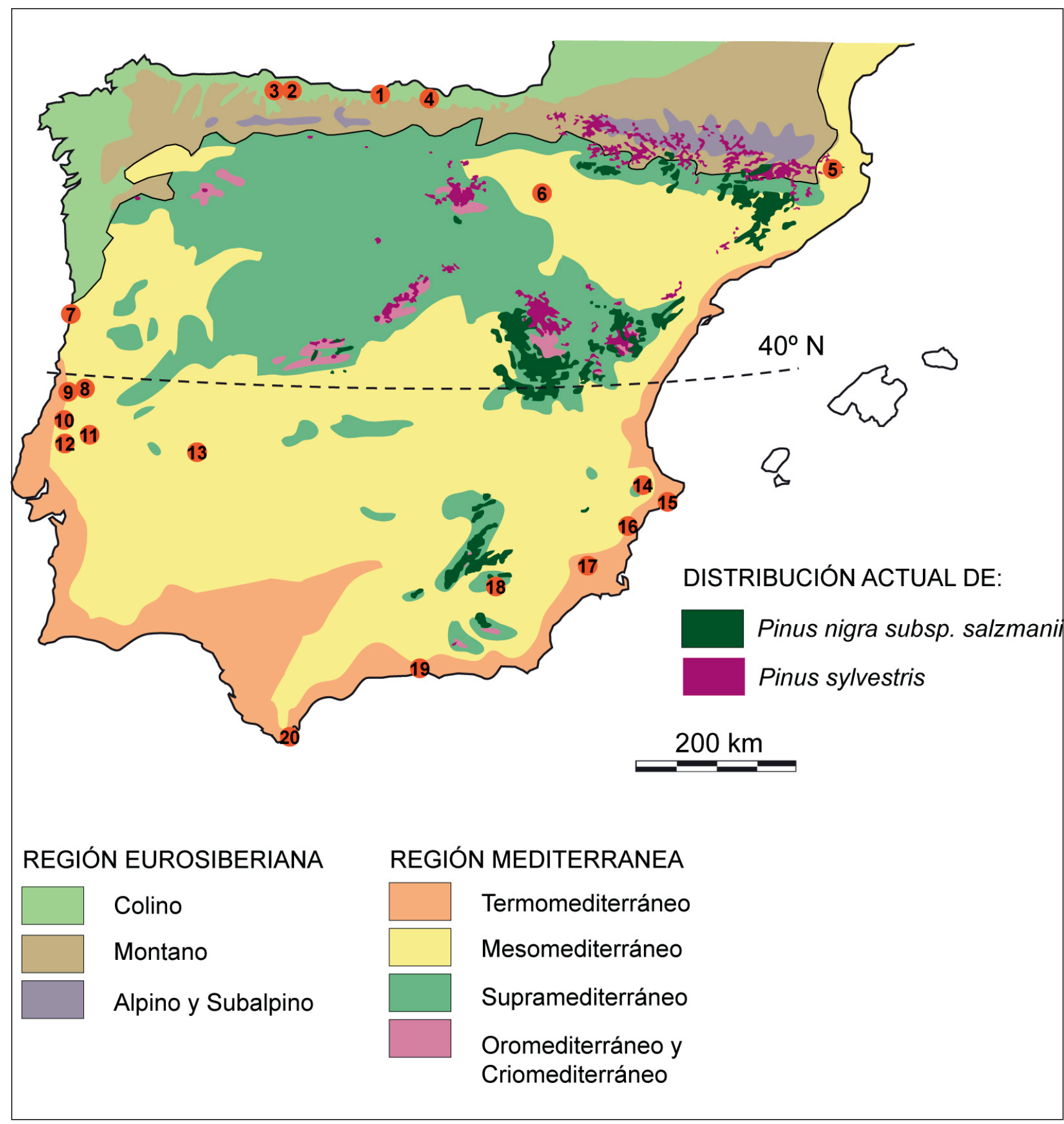

\ Figura 1. Situación de los yacimientos en el mapa biogeográfico actual de Iberia, mostrando además la distribución actual de pino albar (Pinus sylvetris) y pino salgareño (Pinus nigra). Los números corresponden con los sitios indicados en la tabla 2

los yacimientos el tamaño medio de los carbones está en torno a 3-4 $\mathrm{mm}$, esto permite su identificación botánica con facilidad. En este trabajo, para facilitar la lectura e ilustrar la interpretación fisionómica de los paisajes (pinares, enebrales, matorrales) sólo hemos representado los datos cuantitativos de los niveles arqueológicos que tienen más de 100 fragmentos de carbón identificados (Figs. 3, 4, 5 y 6). Finalmente, la interpretación paleoecológica se basa, además, en las necesidades ecológicas de las plantas identificadas (Fig. 7).

\section{CARBÓN Y RADIOCARBONO}

El patrimonio arqueológico es escaso y los recursos económicos para su estudio mucho más, por tanto, debemos ser muy eficaces para obtener la máxima información de los restos materiales. En el análisis del carbón, el protocolo correcto implica primero la identificación botánica y después datar por el método convencional o por AMS el género o especie vegetal más adecuado con el problema que queramos resolver (Badal 2008; Carrión et al. 2010). Es lamentable 


\begin{tabular}{|c|c|c|c|c|c|c|c|c|}
\hline Sitio & Yacimiento & Niveles & Taxón & Fecha BP & Arqueología & Laboratorio & Método & Referencia \\
\hline 1 & Cueva de Altamira & III & Hueso & $18540 \pm 540$ & Solutrense superior & GifA-90045 & AMS & Valladas et al. 1992 \\
\hline 2 & Cueva de el Buxu & $\begin{array}{l}1,2,3 \text { zona interior "alpha" } \\
\text { Nivel } 2 \text { Hogar Zona B/1A }\end{array}$ & & & Solutrense superior & & & Uzquiano $1992 \mathrm{a}, \mathrm{b}$ \\
\hline 3 & Cueva de la Güelga & 1 & & & Solutrense superior & & & Uzquiano $1992 \mathrm{a}$ \\
\hline 4 & Cueva de Cobrante & 4,3 & & & Solutrense superior & & & Uzquiano 2009 \\
\hline 5 & Cueva de l'Arbreda & & & & Solutrense y Gravetiense & & & Ros 1985 \\
\hline 6 & Cueva del Gato & 2 & $\begin{array}{l}\text { Carbón sin identificar } \\
\text { Hueso sin identificar }\end{array}$ & \begin{tabular}{|l|}
$18090 \pm 90$ \\
$18850 \pm 100$ \\
$18260 \pm 130$ \\
$18650 \pm 140$ \\
$17700 \pm 70$
\end{tabular} & Badeguliense & & & Blasco y Rodanés, 2009 \\
\hline 7 & Cortegaça - Playa & Playa & Madera Pinus sylvestris & $20700 \pm 300$ & Natural & KSU-2203 & & Granja, Carvalho, 1995 \\
\hline \multirow{2}{*}{8} & \multirow{2}{*}{ Buraca Grande } & $9 \mathrm{~A}$ & Carbón sin identificar & $17850 \pm 200$ & Solutreo-Gravetiense & Gif-9502 & Conven. & Aubry et al. 1997,2011 \\
\hline & & 9B & Olea europaea & $7022 \pm 41$ & Intrusiva & T18816A & AMS & Carrión et al. 2010 \\
\hline 9 & Buraca Escura & $\mathrm{C} 2 \mathrm{~A}$ & Equido sp. & $21820 \pm 200$ & Proto-Solutrense & OxA-5524 & AMS & Aubry et al. 2001;2011 \\
\hline 10 & Lagar Velho & 9 & Carbón sin identificar & $20200 \pm 180$ & Solutrense Medio & OxA-8419 & & Zilhão y Trinkaus, 2002 \\
\hline \multirow{2}{*}{11} & \multirow{2}{*}{ Gruta do Caldeirao } & $\mathrm{H}$ & Capra pyrenaica & $19900 \pm 260$ & \multirow{2}{*}{ Solutrense Medio } & OxA-1939 & AMS & \multirow{2}{*}{ - Zilhão 1997} \\
\hline & & $\mathrm{H}$ & Hueso sin identificar & $20530 \pm 270$ & & OxA-2511 & AMS & \\
\hline \multirow{3}{*}{12} & \multirow{3}{*}{ Lapa do Anecrial } & 1 & Carbón sin identificar & $20520 \pm 100$ & Solutrense Medio & GrA-1219 & AMS & \multirow{3}{*}{ Almeida et al. 2007} \\
\hline & & \multirow{2}{*}{2} & Erica sp. & $21560 \pm 220$ & \multirow{2}{*}{ Gravetiense term./Proto-Sol. } & OxA-5526 & AMS & \\
\hline & & & Carbón sin identificar & $21560 \pm 680$ & & ICEN-964 & Conven. & \\
\hline \multirow{2}{*}{13} & \multirow{2}{*}{ Cueva de Maltravieso } & \multirow{2}{*}{ A } & Pinus tipo mediterráneo & $19930 \pm 100$ & \multirow{2}{*}{ Peleolítico superior pleno } & Poz-30460 & AMS & \multirow{2}{*}{ Canals et al. 2010} \\
\hline & & & Pinus tipo mediterráneo & $17840 \pm 90$ & & Poz-30469 & AMS & \\
\hline 14 & Cueva de Santa Maira & CG II-12 & Pinus nigra-sylvestris & $19910 \pm 100$ & Solutrense & Beta-317412 & AMS & Inédita \\
\hline \multirow{10}{*}{15} & \multirow{10}{*}{ Cova de les Cendres } & $\mathrm{H}-19$ & Pinus nigra & $20430 \pm 170$ & Intrusiva/Neolítico & Beta- 116625 & AMS & Badal 2006 \\
\hline & & IX & Pinus nigra & $19650 \pm 160$ & Intrusiva / Neolítico & Beta-142285 & AMS & Badal 2006 \\
\hline & & $\mathrm{YIV}$ & Pinus nigra & $20280 \pm 80$ & Croy finol Sol iniciol & Beta-287544 & AMS & Villaverde et al. 2010 \\
\hline & & Xiv & Pinus nigra & $21230 \pm 180$ & Grav. minal - sol. minclal & Beta-142282 & AMS & Villaverde 2001 \\
\hline & & $\mathrm{YUU}$ & Pinus nigra & $18920 \pm 180$ & ISolutrence solucionodo & Beta-118026 & AMS & Villaverde et al. 2010 \\
\hline & & AIII & Pinus nigra & $18750 \pm 130$ & Sorutrense evolucionado & Beta-118027 & AMS & Villaverde et al. 2010 \\
\hline & & & Olea europaea & $6660 \pm 50$ & Intrusivo / Solutrense evol. & Beta-118025 & AMS & Carrión et al. 2010 \\
\hline & & XIIB & Pinus nigra & $17230 \pm 130$ & & Beta-118024 & AMS & Villaverde 2001 \\
\hline & & DID & Pinus nigra & $17210 \pm 60$ & Solutrense evolucionado & Beta-287543 & AMS & Villaverde et al. 2010 \\
\hline & & & Pinus nigra & $16790 \pm 60$ & & Beta-287542 & AMS & Villaverde et al. 2010 \\
\hline 16 & Cueva de la Barriada & Hogar 6 & Juniperus sp. & $19970 \pm 100$ & Inédito & Beta-296224 & AMS & Inédito \\
\hline & & I & & & Solutreo-Gravatiense & & & \\
\hline & & III & Juniperus sp. & $17.360 \pm 180$ & Solutreo-Gravatiense & Ly-5.219 & Conven. & \\
\hline 17 & Ratlla del Bubo & II-III & & & Solutreo-Gravatiense & & & Badal y Carrión 2001 \\
\hline & & III-IV & & & Solutreo-Gravatiense & & & \\
\hline & & IV & & & Solutreo-Gravatiense & & & \\
\hline 18 & Abrigo de la Boja & SW18E & Juniperus sp. & $20980 \pm 110$ & Solutrense inferior & VERA-5213 & AMS & Zilhão et al. 2010 \\
\hline 19 & Cueva de Ambrosio & II & Carbón sin identificar & $16.500 \pm 280$ & Solutrense superior evol. & Gif-7276 & Conven. & Rodriguez-Ariza 2005 \\
\hline & & NV8/s (C4 VII) & Pinus pinea & $11.910 \pm 100$ & Intrusivo / Solutrense C (superior) & GifA-102.019 & AMS & Jordá y Aura, 2008 \\
\hline & & $\mathrm{N} V 8$ & Pinus pinea & $12.340 \pm 60$ & Intrusivo / Solutrense C & Beta-189.081 & AMS & Jordá y Aura, 2006 \\
\hline & Cueva de Neria & NV 8/s (Hogar) & Carbón & $17940 \pm 200$ & Solutrense C & UBAR 98 & Conv & Jordá y Aura, 2008 \\
\hline 20 & Sala del Vestíbulo & NV 81 & Carbón & $18420 \pm 530$ & Solutrense B2 & UBAR 158 & Conv & Jordá y Aura, 2008 \\
\hline & & |Nvo & Quercus sp. caducifolio & $11970 \pm 50$ & Intrusivo / Solutrense B3 & Beta-313434 & AMS & Inédita \\
\hline & & NV 9 (C4 VIII) & Pinus pinea & $21140 \pm 190$ & Solutrense B1 (Inferior) & GifA-102.021 & AMS & Jordá y Aura, 2006 \\
\hline & & NV10 & & & Solutrense B1 (Inferior) & & & \\
\hline $21 \mathrm{l}$ & Gorbam's Cave & IUR $(G O R \operatorname{ch}-5$ y $G O R \operatorname{ch} 4)$ & Carbón sin identificar & $18440 \pm 160$ & Solutrens & Beta-181893 & & Carrión et al. 2008 \\
\hline 21 & Gomant s cave & 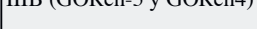 & \begin{tabular}{|l|} 
Carbón sin identificar \\
\end{tabular} & $16420 \pm 120$ & pointiense & Beta-184042 & & Carrión et al. 2008 \\
\hline
\end{tabular}

A Tabla 1. Yacimientos con niveles solutrenses considerados en el texto.

que se gaste muchísimo dinero en dataciones radiocarbono y en ese proceso se destruya una información preciosa, la historia de las plantas y su distribución. Para demostrar este derroche tomaremos como ejemplo el reciente artículo de Jordá y Aura (2008) donde se hace un exhaustivo análisis de las fechas realizadas en la Cueva de Nerja desde la primera datación de radiocarbono publicada en 1970 hasta 2008. En la Fig. 2 se observa que antes de datar se identificaron algunos materiales: Mytilus, Capra pyrenaica, Ovis, hueso humano, semilla, bellotas, cereales, Pinus y el resto de dataciones (49) se hicieron sobre carbón sin identificar. Si se hubieran identificado los género y las especies, que se enviaron a datar, en esas 49 muestras, tendriamos la historia de las especies vegetales con una cronológica precisa, lo que ayudaría a conocer la flora ibérica a lo largo del tiempo, pero además, probablemente, se hubieran evitado fechas incoherentes con los contenidos arqueológicos. No olvidemos que la única fecha directa es el material que se data y por inferencia se correlaciona con el contexto arqueológico, que pueden ser coetáneo o no según la existencia de procesos postdeposicionales.

En la Cueva de Nerja sí que se ha identificado y datado carbón y brácteas de piña de pino piñonero (Pinus pinea) (Tab. 1) lo que nos ayuda a ser rotundos a la hora de saber que el sur de lberia fue la zona más cálida de Europa durante el Solutrense (OIS 2) y que el pino piñonero es autóctono de las costas andaluzas desde el Pleistoceno superior (Badal 1990, 1998; Metcalfe, 1958).

En la Cova de les Cendres, todos los carbones datados han sido previamente identificados. Con ello hemos podido demostrar que Pinus nigra siempre da cronologías del Pleistoceno, incluso cuando se encuentra en niveles holocenos (Tab. 1) (Badal 2006). Por ejemplo, como se observa en la tabla 1, las dos primeras fechas de Pinus nigra son del Solutrense pero se encontraron en los primeros niveles neolíticos (nivel $\mathrm{H}-19$ y IX) y se dataron justamente para demostrar una contaminación por la actividad humana durante el Neolítico al realizar fosas y silos que profundizaban en los nive- 


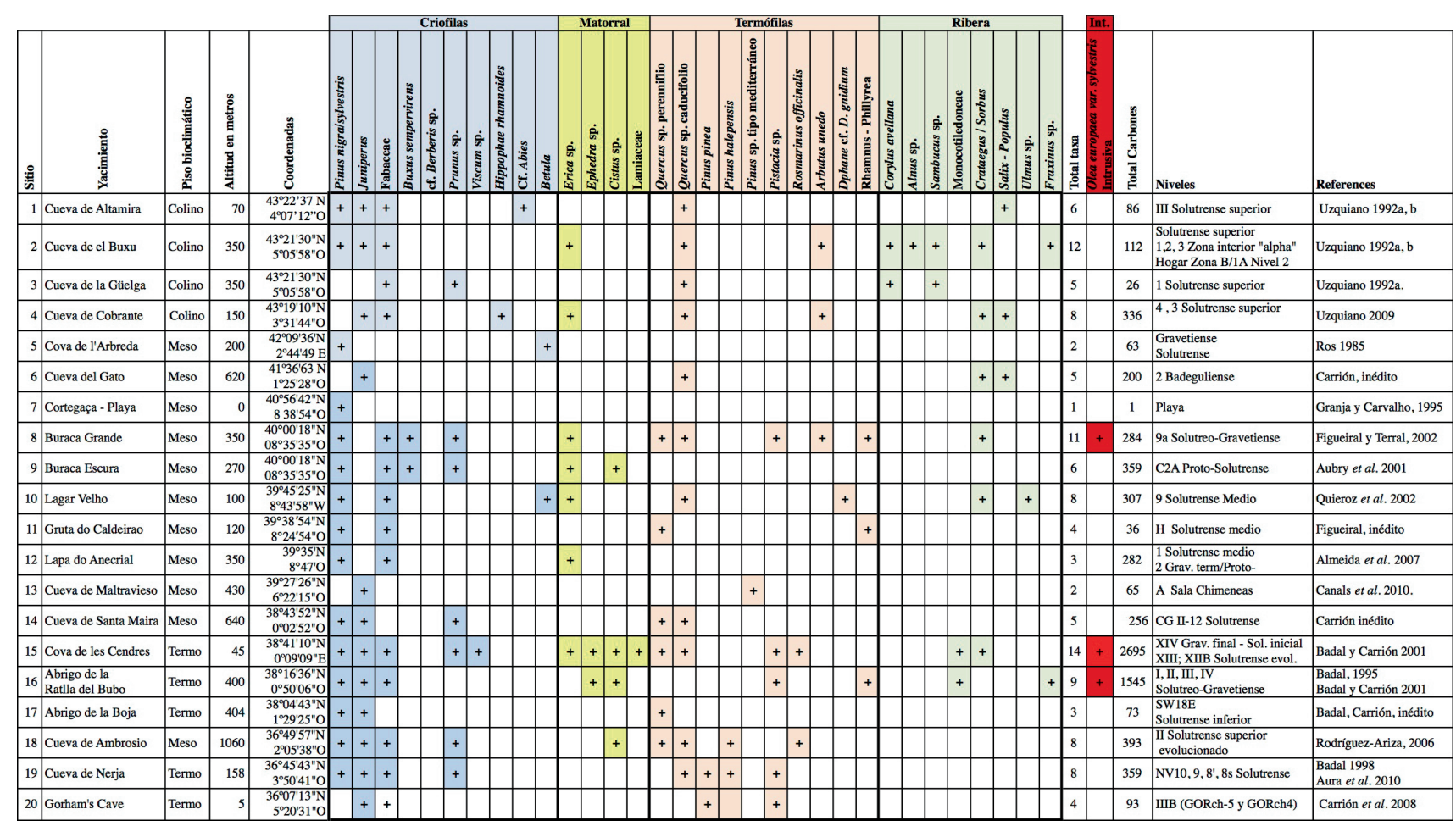

\ TABLA 2. Situación biogeográfica de los yacimientos y flora identificada en los carbones.

les paleolíticos. También hay que llamar la atención sobre la fecha de Olea (Tab. 1) porque es el caso inverso que discutiremos más adelante.

Finalmente, queremos llamar la atención sobre el gran número de yacimientos con niveles solutrenses que existen en la península donde se han realizado dataciones radiocarbono sobre carbones $y$, sin embargo, son muy pocos los que tienen estudios antracológicos publicados. La publicación de Banks et al. (2009: 2856-2859) recoge 75 yacimientos con niveles solutrenses en España y Portugal; de los cuales solamente en unos 20 hay análisis del carbón para conocer las condiciones ecológicas en las que vivían los grupos solutrenses.

En algunos casos, es evidente que las condiciones ambientales y los procesos tafonómicos son los responsables de la destrucción total del carbón, pero en la mayoría de los yacimientos son los métodos arqueológicos los responsables de la pérdida de información ecológica y etnográfica. Por eso hacemos una llamada a todos los directores de excavaciones para que se haga un esfuerzo de muestreo y se recupere el patrimonio que no se ve pero que, si se busca, se encuentra. Además, el carbón puede ayudar a resolver problemas de capital importancia para la interpretación arqueológica, tafonómica, etc.

\section{RESULTADOS}

Se han tomado en consideración 20 yacimientos arqueológicos, con un total de 32 niveles que van desde inicios hasta el final del Solutrense, con grandes hiatus (Tabs. 1 y 2). De la tabla 2 se ha excluido la Cueva de la Barriada porque está en proceso de análisis, de momento sólo tenemos la datación de un Juniperus que se indica en la tabla 1. En el tabla 2 se observa que cuantos más carbones se analizan en un yacimientos más diversidad de flora hay, es decir, hay una correlación entre número de carbones analizados y número de taxones identificado (Tab. 2). Por otro lado, los géneros más criófilos (Pinus nigra y/o P. sylvestris, Juniperus) están en todos los territorios; los géneros y especies más termófilos se encuentran en los yacimientos al sur del paralelo $40^{\circ} \mathrm{N}$ (Pinus pinea, Pistacia, Rosmarinus officinalis, Quercus sp. perennifolios) y las especies más exigentes en humedad se encuentran en la zona norte peninsular (Corylus, Alnus, Ulmus, Salix).

Las secuencias más completas son la de la Cova de les Cendres (Alicante) y Cueva de Nerja (Málaga) (Badal y Carrión 2001; Aura et al. 2010) aunque tampoco tienen la secuencia del Solutrense completa. En la Cova de les Cendres, en el Solutrense inicial - Gravietiense final (nivel XIV), los porcentajes de los taxones identificados permiten inferir un paisaje de pinares criófilos (Pinus nigra y/o P. sylvestris) con sotobosque de fabáceas leñosas y pocos enebros. Un hiatus estratigráfico impide ver como se instalan los enebrales - matorrales de fabáceas leñosas que observan en todos los niveles del Solutrense evolucionado. En la Cueva de Nerja la dinámica es similar aunque aquí son las fabáceas las que dominan los matorrales y apenas hay enebros. Los demás yacimientos tienen una sola fase del Solutrense 


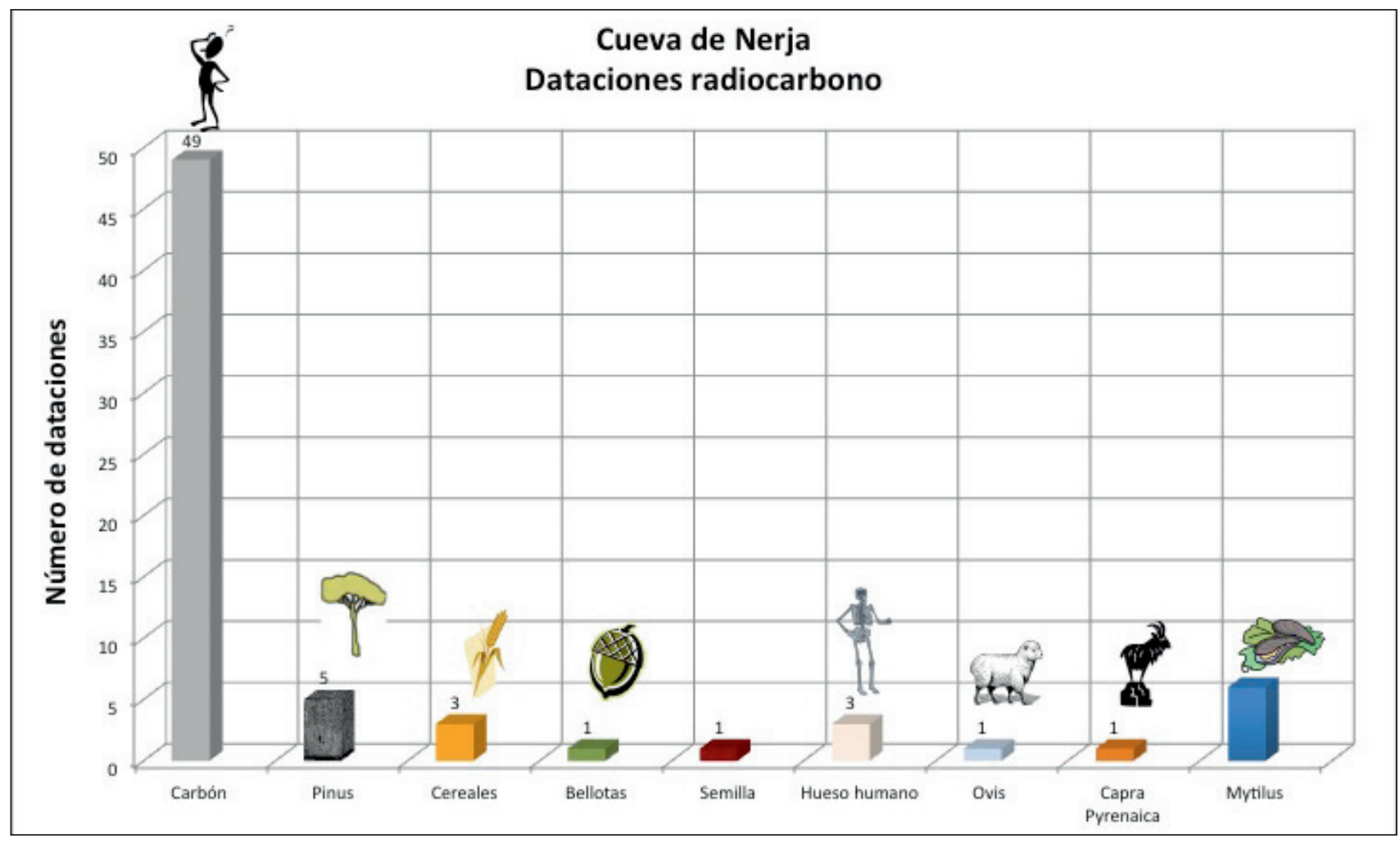

A Figura 2. Dataciones radiocarbono realizadas en los materiales de la Cueva de Nerja. Datos a partir de Jordá y Aura, 2008 , tabla 1: $244-245$.

con un número de carbones suficientemente representativo. La flora identificada en el conjunto de yacimientos se puede agrupar en cuatro categorias en función de sus necesidades ecológicas, dando diferentes formaciones vegetales (Tab. 2).

- Flora criófila o de requerimientos fríos, que incluye géneros o especies que viven, actualmente, en el piso supramediterráneo o superiores, donde la TMA (Temperatura Media Anual) es inferior a $13^{\circ} \mathrm{C}$. Así: Pinus sylvestris, Pinus nigra, Juniperus sp., Fabaceae, Prunus sp. Buxus sempervirens, Berberis sp. Géneros claramente eurosiberianos como Betula sp. Hippophae rhamnoides, Abies sólo se encuentran en los sitios del norte peninsular. Dentro de ese conjunto los que alcanzan mayor frecuencia son Juniperus, y Pinus, esto se interpreta como los principales componentes de las formaciones vegetales más importantes del Solutrense: los pinares fríos y los enebrales y/o sabinares fríos y secos.

\section{Pinares criófilos}

Los pinos son buenos indicadores de las condiciones termoclimáticas pero con el carbón no siempre se pueden distinguir la especie con seguridad; aunque afortunadamente se pueden discriminar muy bien los pinos criófilos (Pinus nigra, P. sylvestris, P. uncinata) de los pinos termófilos ( $P$. halepensis, $P$. pinea y $P$. pinaster). En base a ello, se distinguen los pinares fríos, que actualmente viven en las montañas ibéricas, de los cálidos de las tierras bajas.

En el Pleniglacial, Pinus sylvestris y/o P. nigra son los más ubicuos y la frecuencia que alcanzan en los yacimientos depende de su situación geográfica. Al norte del paralelo $40^{\circ} \mathrm{N}$, Pinus sylvestris está en pequeñas cantidades en los yacimientos de la región eurosiberiana (Altamira, Buxu) y en L'Arbreda. Al sur del paralelo $40^{\circ} \mathrm{N}$, se encuentra en todos los yacimientos de Portugal ( $\pm 20 \%$ ) y tal vez, junto a Pinus nigra en el resto de yacimientos peninsulares (Figueiral y Terral 2002; Figueiral y Carcaillet, 2005; Queiroz et al. 2002). En Cova de les Cendres, Sta. Maira y Cueva de Nerja, los restos de pinos criófilos representan entre el $25-70 \%$ de los carbones identificados (Fig. 3) (Badal y Carrión 2001; Aura et al. 2010).

Las dataciones radiométricas realizadas sobre carbón de Pinus nigra - P. sylvestris lo sitúan a lo largo de todo el Solutrense entre el nivel del mar y los 1000 metros de altitud (Tab. 1).

\section{Enebrales - Sabinares}

Con la anatomía de la madera no se pueden distinguir las especies de Juniperus, esto dificulta la inferencia térmica, pero un punto en común de todas las especies de Juniperus es su resistencia a condiciones extremas de aridez y temperatura; además son heliófilas y frugales por lo que son buenos pioneros para colonizar suelos pobres y descubiertos del Pleniglacial. 


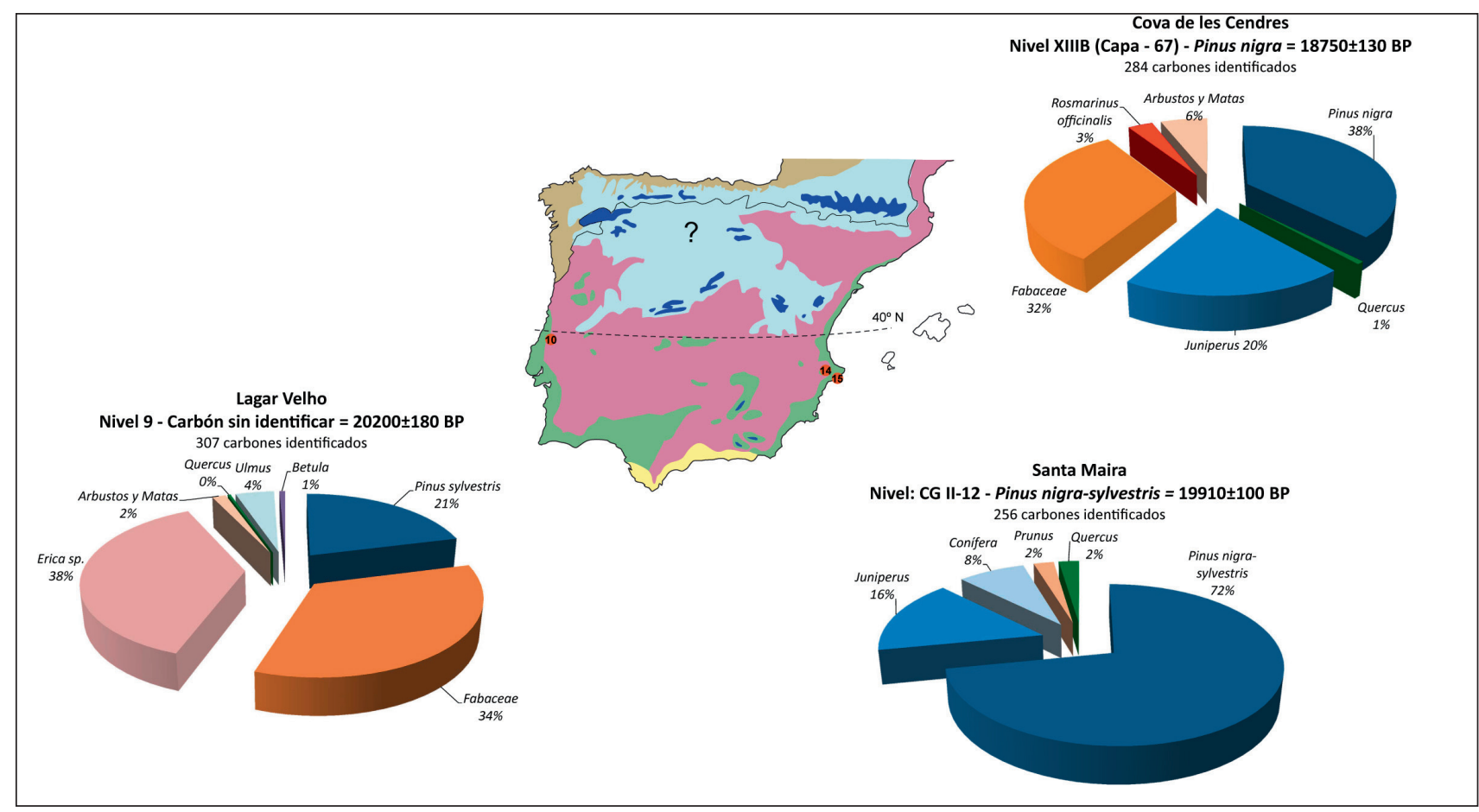

ム FiguRa 3. Pinares criófilos y mapa hipotético de las condiciones bioclimáticas en Iberia durante el Solutrense.

Los restos de Juniperus sp. dominan los espectros antracológicos de los yacimientos situados en las zonas más secas y áridas de la región mediterránea - Cueva del Gato, Cueva Ambrosio, Ratlla del Bubo y La Boja- (Fig. 4) y tienen altos porcentajes en Cova de les Cendres y Sta. Maira (Badal y Carrión, 2001; Rodríguez-Ariza 2005). Los Juniperus siempre van acompañados de matorral de ecología fría y seca (Fabáceas leñosas, Artemisia, Ephedra, etc.). Por tanto, las zonas más secas de la península lbérica son las mismas ahora que durante el Último Máximo Glacial, es decir, zonas del valle del Ebro y el SE peninsular. Esto debe estar en relación con la circulación atmosférica global, que no ha variado sustancialmente.

En la región eurosiberiana los yacimientos tienen pocos carbones analizados, lo que dificulta su interpretación cuantitativa. En Cobrante los carbones de Juniperus sp. y Salix son los más abundantes (Fig. 4). En los otros yacimientos Juniperus están junto a géneros y especies frías como Abies, Hippophae rhamnoides. En Portugal no se han identificado Juniperus en ningún yacimiento solutrense.

En el conjunto de yacimientos, no sabemos de qué especies de Juniperus se trata porque con el carbón no se puede llegar a ese rango de identificación, pero deben ser de alta montaña: J. thurifera; J. communis o incluso J. nana que en la actualidad crece en la zona de montaña alpina y en las cumbres de las montañas mediterráneas. Todos ellos soportan inviernos frios hasta $-25^{\circ} \mathrm{C}$ y veranos calurosos ( $J$. thurifera hasta $40^{\circ} \mathrm{C}$ ), por tanto están perfectamente adaptados a condiciones extremas de temperatura y aridez. No se descarta la presencia de J. oxicedrus y J. phoenicea en las zonas más cálidas. La diferencias pluviométricas entre las regiones se pueden inferir con las plantas acompañantes, por ejemplo, en Cobrante la abundancia de sauce indica una vegetación de ribera importante que puede ser debida a un régimen de lluvias regular y abundante (Fig. 4).

- Matorral: Tanto los pinares como los enebrales y/o sabinares presentan un cortejo de matas y arbustos de ecología fría, entre ellos: Fabáceas leñosas, Prunus sp. Berberis, Buxus, etc. Por otro lado, una serie de arbustos y matas, determinados en el rango de género o familia, que pueden vivir en formaciones frías o más termófilas, según sean unas especies $u$ otras, por lo que tienen amplia tolerancia térmica y de humedad, es el caso de Erica, Ephedra, Cistus, Artemisia y Lamiaceae (Tab. 2).

Las matas y los arbustos están en todos los yacimientos con mayor o menor cantidad, en algunos casos formarian paisajes abiertos con diversidad de fabáceas leñosas, brezos y labiadas (Cova de les Cendres, Cueva de Nerja, Lagar Velho) (Figs. 3 y 4). Con la anatomía de la madera, en general, no se puede identificar los géneros ni las especies de las Fabáceas leñosas. Esta familia alberga gran diversidad de especies, con fisionomía y ecología muy dispar desde las muy áridas y secas hasta las muy húmedas y frías. Dentro de esta familia están las genistas, aulagas, retamas, etc.

- Flora de ribera o de alto requerimiento hídrico, que forma los bosques galería en el fondo de los valles 


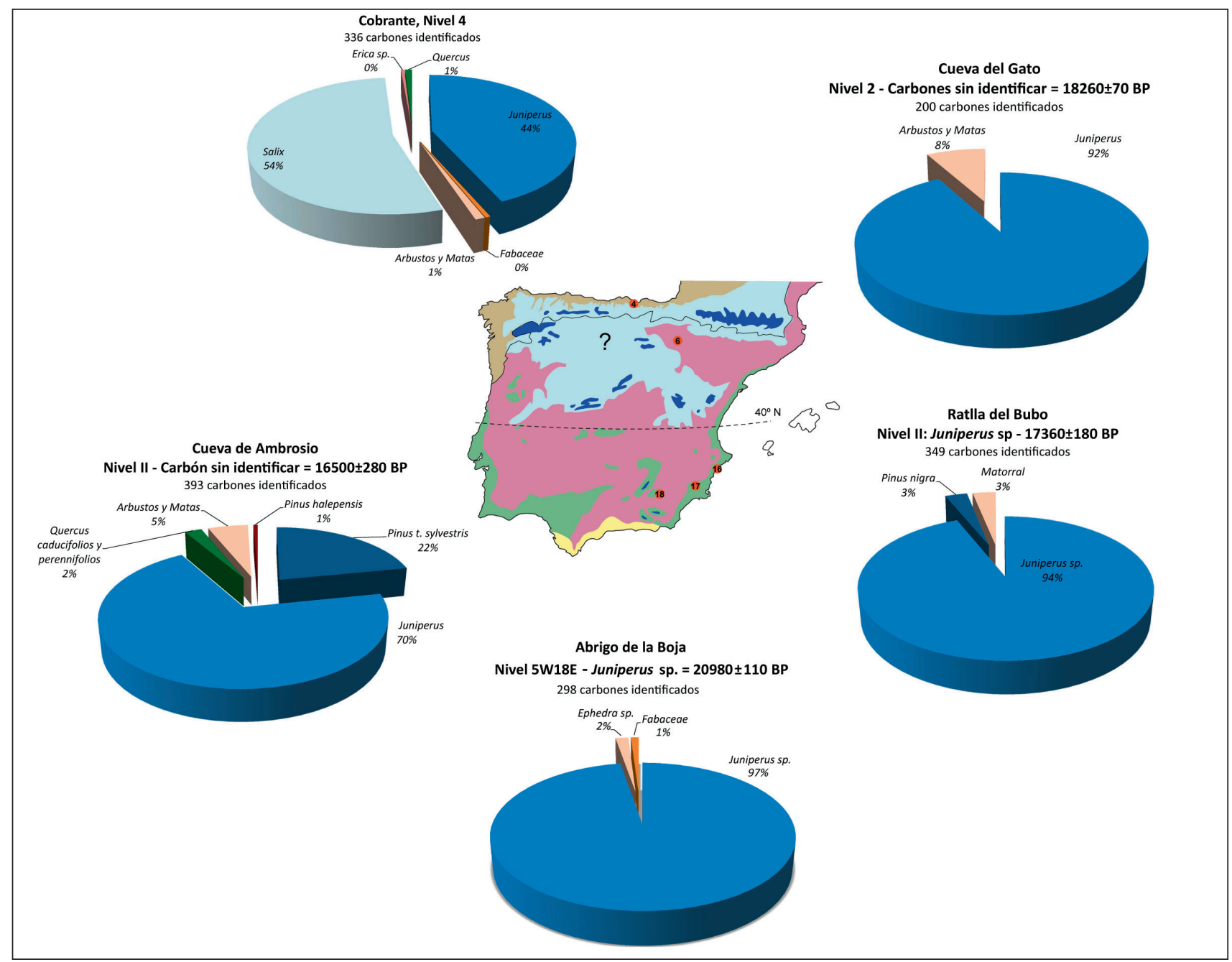

A FIgURA 4. Enebrales - sabinares y mapa hipotético de las condiciones bioclimáticas en Iberia durante el Solutrense.

o zonas húmedas. Corylus avellana y Alnus sólo se han encontrado en yacimientos eurosiberianos y Ulmus sólo en Lagar Velho (Portugal). En el resto géneros (Fraxinus, Salix y/o Populus, Monocotiledónea, Crataegus) no se observa una predilección regional.

- Flora termófila o de requerimientos cálidos son los géneros y especies que en la actualidad viven desde el piso termomediterráneo hasta el supramediterráneo, siendo la TMA superior a $13^{\circ} \mathrm{C}$. Entre otros, Pinus pinea, Pinus halepensis, Quercus sp. perennifolios, Pistacia sp. Rosmarinus officinalis, etc. Estos taxones sólo se encuentran en unos pocos yacimientos y siempre situados al sur del paralelo $40^{\circ} \mathrm{N}$. En algunas zonas pudieron formar pinares, carrascales y matorrales esclerófilos de ecología cálida, en especial en las zonas bajas (0 - 300 m. altitud) del este y sur peninsular. Comentaremos sólo los taxones más significativos como bioindicadores termófilos en el siguiente apartado de los refugios en el sur de lberia.

\section{LOS REFUGIOS DEL SUR DE IBERIA}

Mucho se ha discutido sobre los refugios de flora en el sur de Europa, pero ¿qué datos directos tenemos para demostrarlo? Lo más directo es datar las especies de ecología cálida pero también datar las de ecología fría para ver si conviven en tiempo y lugar (Carrión et al. 2010). Esto nos ayuda a precisar las condiciones ecológicas de cada yacimiento en un momento preciso de tiempo. Repetimos que siempre se ha de datar el género o la especie más significativa desde el punto de vista ecológico, cultural, tafonómico, etc. Nunca se debe datar un carbón sin identificar.

La flora más termófila (Pinus pinea, Pinus halepensis, Quercus sp. perennifolio, Rosmarinus officinalis, Pistacia sp.) sólo se encuentra en los yacimientos más meridionales, por poner un límite geográfico, al sur del paralelo $40^{\circ} \mathrm{N}$ (Fig. 5).

El pino piñonero (Pinus pinea) está a lo largo de toda la secuencia de la Cueva de Nerja en carbón, brácteas de piñas, cáscaras de piñón y los propios piñones. Ha sido datado directamente por AMS a lo largo de todo el Paleolítico superior 


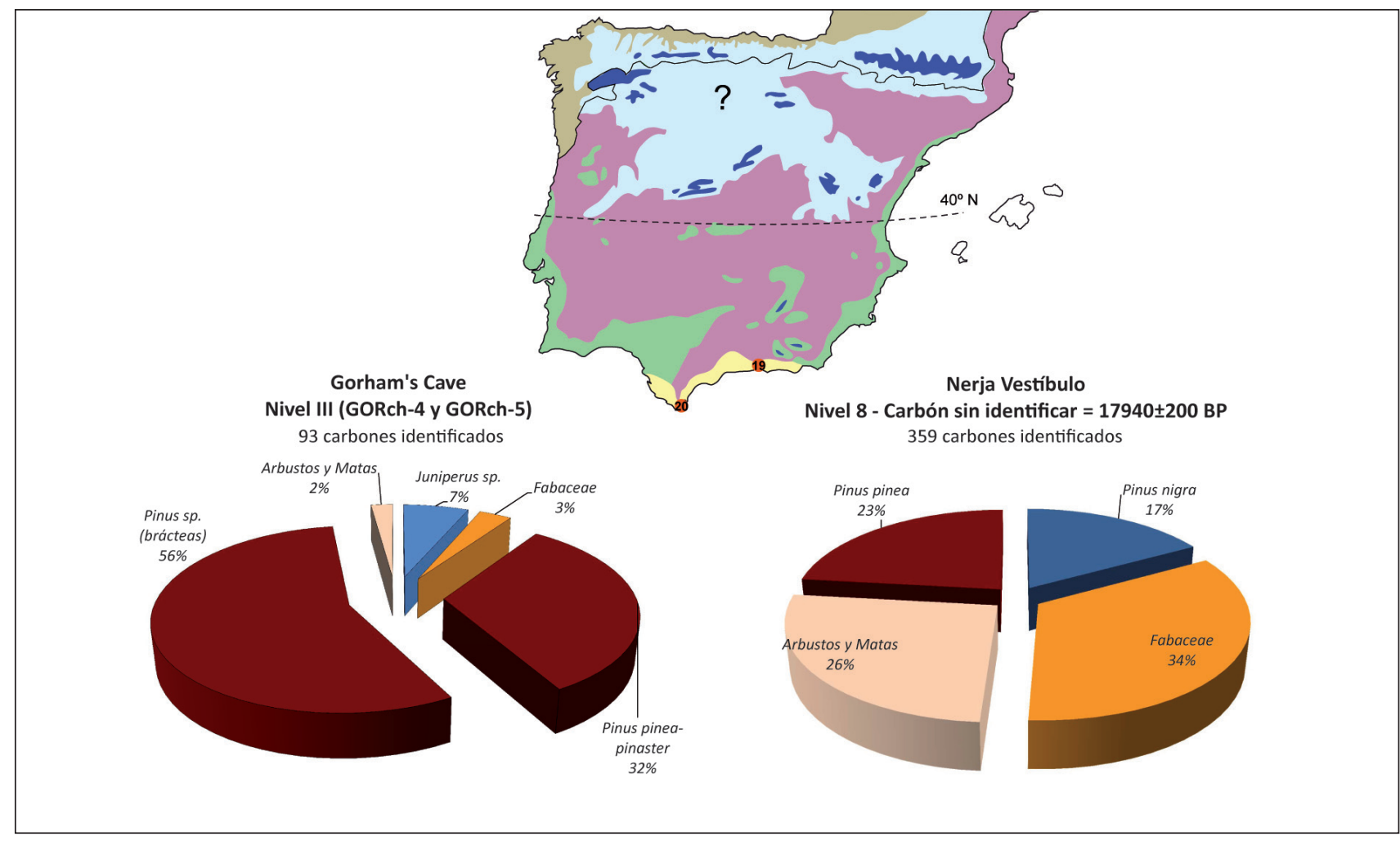

A Figura 5. Formaciones termófilas y mapa hipotético de las condiciones bioclimáticas en Iberia durante el Solutrense.

(Tab. 1) aunque algunos fragmentos muestren intrusiones estratigráficas. Su leña fue poco quemada, porque, probablemente, los grupos humanos solutrenses hicieron una gestión conservadora de los pinares de pino piñonero con la finalidad de recolectar masivamente las piñas, visto el valor nutritivo de los piñones (Badal 1990, 1998, 2001). Así que, podemos afirmar que recolectaban las piñas enteras sistemáticamente durante todo el Solutrense. En la cueva se procesaban para extraer los piñones que finalmente consumian los humanos. En Gorham's Cave, Metcalfe (1958) identifico brácteas de pino piñonero en niveles musterienses. En la publicación de Carrión et al. (2008) el nivel III tiene hasta un 50\% de restos de piñas de Pinus pinea/pinaster. Aunque los autores no las identifican en el rango de especie, debe tratarse de brácteas de piñas de pino piñonero y reflejar un comportamiento humano similar al descrito en la Cueva de Nerja, es decir, la torrefacción de los conos enteros para extraer los piñones y posteriormente ser consumidos por su aporte en grasa.

Quercus sp. caducifolio (robles en sentido amplio) está presente de norte a sur aunque no en todos los yacimientos y siempre en muy pequeñas cantidades (Tab. 2). En un nivel solutrense (NV8') de la Cueva de Nerja se halló un sólo carbón de Quercus sp. caducifolio, para comprobar si habia perdurado durante el máximo glacial o era una intrusión holocena, se dató. La fecha Beta-313434: $11970 \pm 50$ BP (Tab. 1) demostró que era una intrusión de los niveles superiores. Las distintas especies de 0 . caducifolios se adaptan bien a la variabilidad térmica, pluviométrica y a los suelos de las distintas regiones peninsulares. No obstante, la poca frecuencia de sus restos, en todos los yacimientos ibéricos, indica que no formarían robledales densos $y$, tal vez, se refugiaban en los cauces de los ríos donde habría más disponibilidad hídrica.

Los carbones de Quercus sp. perennifolio (carrascas, encinas, coscojas, alcornoques) están en pequeñas cantidades en yacimientos al sur del paralelo $40^{\circ} \mathrm{N}$. En la Cova de les Cendres, un carbón de Quercus sp. perennifolio ha sido datado en Beta-303419: $23350 \pm 100$ BP y otro de Rosmarinus officinalis en Beta-295148: $21880 \pm 100$ BP y, aunque pertenecen a niveles del Gravetienses final que no se consideran aquí, sí son significativos porque la curva de Quercus es continua en el Solutrense (1-5\% de los restos) y demuestra la permanencia de las especies cálidas durante el máximo glacial. No conocemos la especie, podría tratarse de coscojares y/o carrascales de fisionomía variada.

Olea europea var. sylvestris es un claro indicador termófilo. En el Holoceno, es muy frecuente y abundante en los yacimientos situados en el actual piso termomediterráneo. Por el contrario, es muy raro hallar carbones de Olea en yacimientos de Paleolítico superior situados en la misma franja bioclimática y cuando se encuentran y se datan (Tab. 1), de momento, siempre han dado fechas holocenas, lo que nos permite dudar de todos aquellos no datados (Carrión et al. 2010). Los altos porcentajes de Olea europaea en niveles solutrenses de Buraca Grande (Fig. 6) plantean serias dudas sobre su procedencia. En Buraca Grande un carbón 


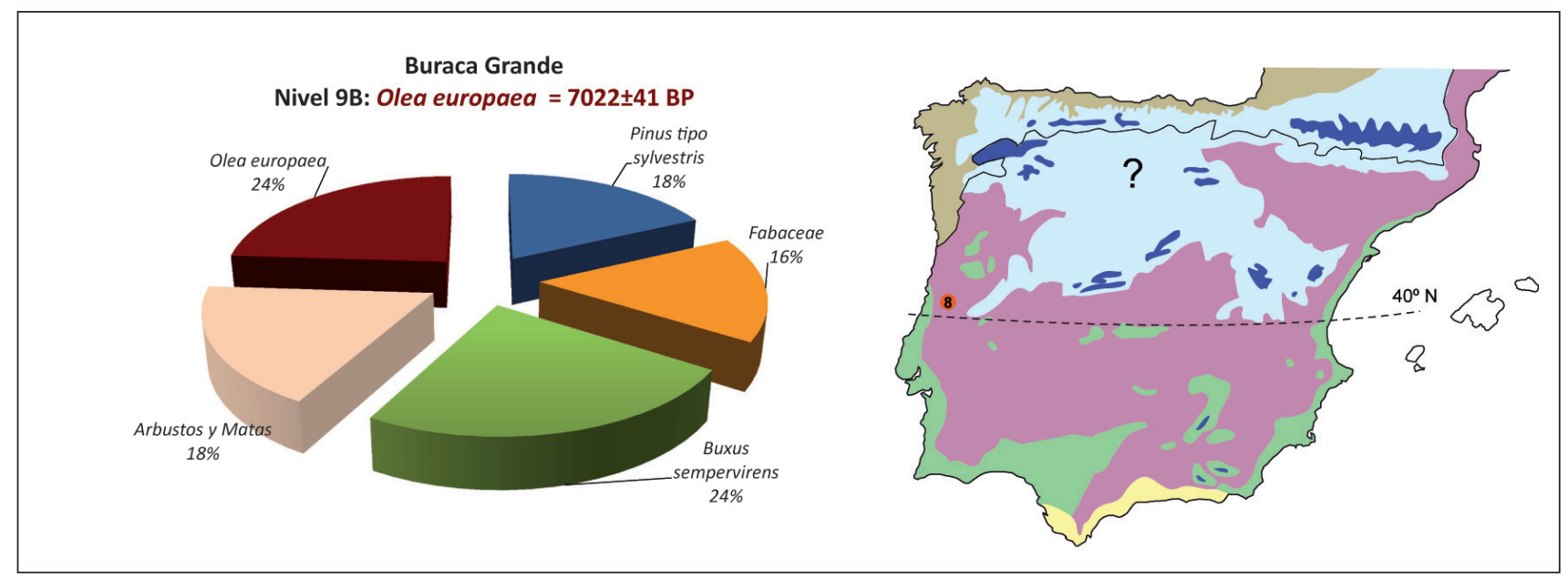

A Figura 6. Yacimiento con flora termófila y criófila como posible consecuencia de procesos tafonómicos.

de Olea ha sido fechado en T18816A: $7022 \pm 41$ BP, lo que demuestra que procede de los niveles superiores del Holoceno, donde sus restos son muy abundantes (Carrión et al. 2010; Figueiral y Terral, 2002). Para dar validez a los datos de Buraca Grande se deberían de datar más carbones de Olea porque de ser cierta su presencia durante el Solutrense sería la única región de Iberia con Olea (Tab. 1).

En la Cova de les Cendres se identificaron unos pocos fragmentos de carbón de Olea en el nivel solutrense XIIIA. Se encontraron en el cuadro A17, cuya excavación genera el corte sagital con la secuencia paleolítica y neolítica. En los niveles neolíticos, los carbones de Olea alcanzan porcentajes importantes, por eso al identificar los carbones de Olea en el nivel solutrense pensamos que podrían venir de desprendimiento del corte por efecto de goteras o de los propios excavadores. No obstante, quisimos hacer una datación directa por si eran paleolíticos y se demostraba que las especies cálidas habian perdurado durante el Pleniglacial. La datación confirmó nuestra primera hipótesis, intrusión neolítica. Lo mismo debe ocurrir en Buraca Grande. (Carrión et al. 2010). En la Ratlla del Bubo se dató otro carbón de Olea situado en los niveles solutreo-gravetienses y la fecha fue histórica, pero no se ha publicado (Terral com. per.). Esto nos alerta sobre los procesos postdeposicionales y se ha visto en otros yacimientos con secuencias de Pleistoceno - Holoceno donde las especies más termófilas (Olea, Pinus halepensis) siempre han dado fechas holocenas (Lucena et al. presente vol.; Zilhão et al. 2010a, y b). Por el momento todos los carbones de Olea encontrados en niveles solutrenses o del Paleolítico superior han dado fechas del Neolítico antiguo (Cendres, Buraca Grande, La Boja) o claramente históricas (Ratlla del Bubo) y todos tenían una explicación tafonómica. En la actualidad no hay ningún resto de Olea, datado por radiocarbono, que dé fechas del Paleolítico superior, lo que hace suponer que: a) desapareció de lberia durante el máximo glacial; b) se refugió en zonas muy pequeñas que no coinciden con el área de captación de leña de las comunidades solutrenses.

\section{DISCUSIÓN}

La exposición anterior demuestra que los datos antracológicos son todavía muy exiguogas para hacer una reconstrucción exhaustiva de la dinámica medioambiental durante el Solutrense. No obstante, los carbones son la prueba directa de los ecosistemas explotados por los grupos humanos $y$, por tanto, de las formaciones vegetales existentes en cada región.

Los pisos bioclimáticos, definidos por Ozenda (1975) y Rivas-Martínez (1983), dan lugar a los pisos o series de vegetación. Cada cinturón o piso tiene unos parámetros térmicos que lo definen y en ellos se desarrolla un paisaje vegetal particular, que estará dominado por las especies que mejor se adapten a los parámetros climáticos de cada piso bioclimático (Fig. 1). Siguiendo esos conceptos, y en base a la ecología de los taxones identificados en los sitios arqueológicos, se puede plantear una hipótesis bioclimática de lberia durante el Solutrense (Fig. 7) con todas las reservas necesarias, puesto que, insistimos, los carbones son el reflejo de la flora local y no se puede extrapolar más allá del radio de acción humana que no siempre es fácil de cuantificar.

Los análisis de los carbones del Solutrense, en sentido amplio, (circa 21500 - 17000 B.P.), indican que en los paisajes circundantes a los sitios habitados crecían coníferas $y$, en concreto, los pinos criófilos y los enebros son los protagonistas durante todo el periodo. Si comparamos la presencia de Pinus sylvestris - P. nigra en yacimientos arqueológicos con su distribución actual (Fig. 1) se constata un descenso altitudinal del orden de 1000 metros y por inferencia, la temperatura debió de ser de unos $10^{\circ} \mathrm{C}$ inferior a la media anual actual. Es decir, las condiciones bioclimáticas de las zonas bajas debieron ser de tipo supramediterráneo (TMA de $8^{\circ}$ a $13^{\circ} \mathrm{C}$ ) 0 montano (TMA de $4^{\circ}$ a $8^{\circ} \mathrm{C}$ ) en la región eurosiberiana.

Pinares criófilos, enebrales y sabinares debian de ocupar amplias áreas peninsulares desde el nivel del mar hasta el límite arbóreo altitudinal que debió ser muy inferior al que 


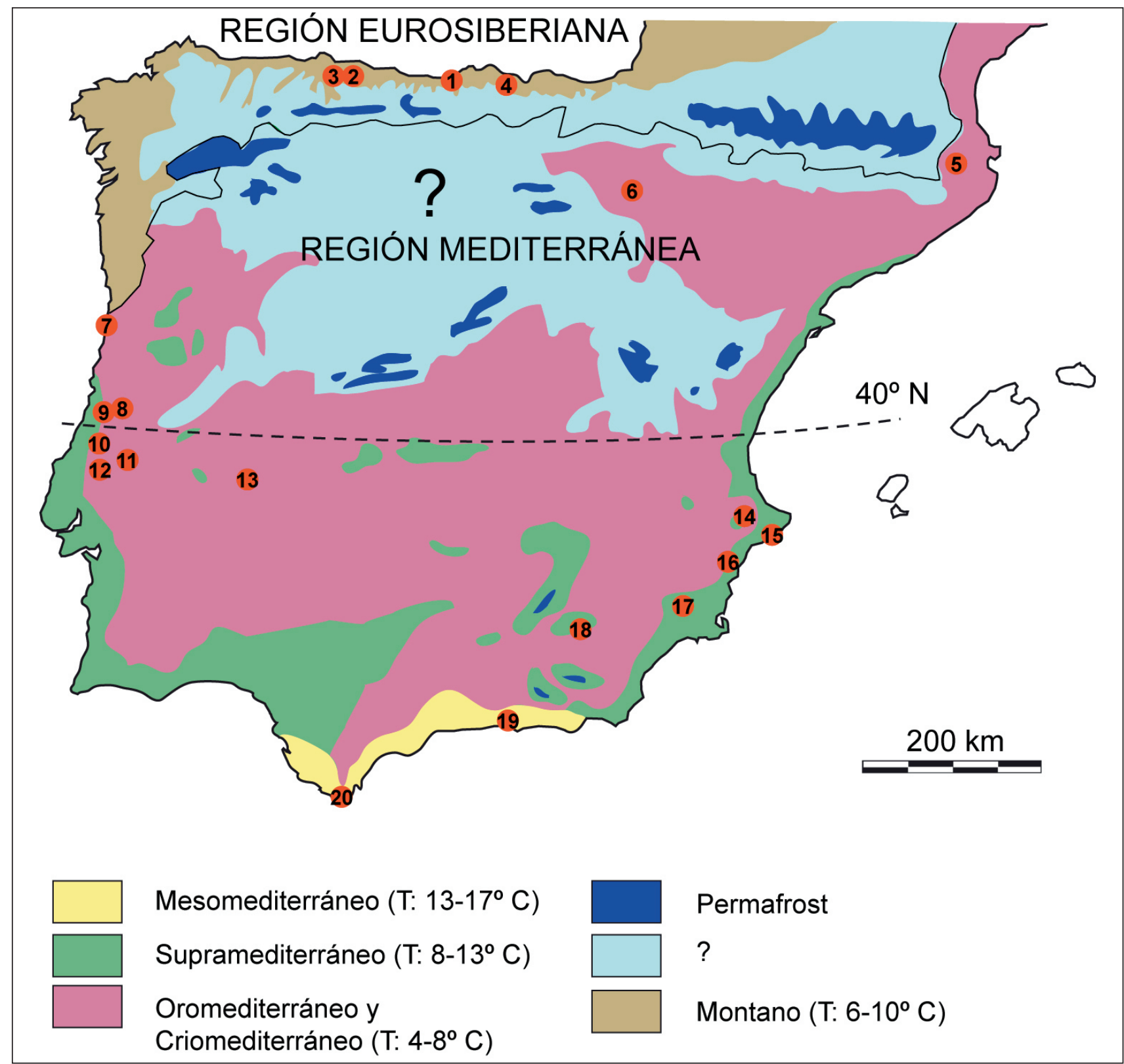

^ Figura 7. Hipótesis bioclimática de Iberia durante el Último Máximo Glacial.

hoy conocemos en las montañas, ya que muchas de ellas estarian cubiertas de nieve permanente a lo largo del año. Algunos autores sitúan el límite arbóreo en torno a los 1000 - 1300 m de altitud (Rubiales 2010; Ramil 1993). Aunque no siempre es fácil distinguir las especies de pinos, seguramente el pino albar ( $P$. sylvestris) se encuentra con mayor frecuencia en los yacimientos arqueológicos de la mitad norte peninsular coincidiendo con la actual región biogeográfica eurosiberiana o zonas más húmedas de la mediterránea por su buena adaptación a la sequía estival. Pinus nigra se encuentra en los yacimientos de la región mediterránea desde el nivel del mar hasta los $1000 \mathrm{~m}$ de altitud (Cueva Ambrosio). En las zonas óptimas se formarían pinares densos, pero si nos atenemos a los espectros antracológicos, en muchos yacimientos pinos y enebros forman un tándem que daría unos paisajes de fisionomía abierta. De todos modos, y como no siempre es fácil distinguir las especies de pinos, es probable que las distintas especies de pinos criófilos vivieran conjuntamente en algunas zonas.

El extremo meridional de Iberia sería la zona más cálida, tal vez, con condiciones bioclimáticas de tipo mesomediterráneo (TMA de 13 a $17^{\circ} \mathrm{C}$ ). De momento los pinares más termófilos, los de pino piñonero, sólo se han documentado en la costa de Andalucia, donde efectivamente perduraron a lo largo del Pleniglacial y fue una fuente de recursos para las poblaciones del sur de lberia: leña, resina y, sobre todo, piñones.

Algunas plantas son buenas indicadoras de las condiciones de humedad y en base a ellas se puede inferir la plu- 
viometría regional. Así, la presencia masiva de Juniperus en algunos yacimientos puede indicar unas condiciones semiáridas o secas (300 - $600 \mathrm{~mm}$ anuales de lluvia) en zonas del valle del Ebro y SE peninsular; por el contrario, las zonas donde abundan Pinus y, en menor medida, Quercus, serían de tipo sub-húmedo (600 - $1000 \mathrm{~mm}$ de media anual) e incluso algunas zonas pudieron recibir mayor cantidad de Iluvia anual como algunas zonas del oeste o del norte peninsular donde hay marcadores hidricos como Quercus, Salix, Betula.

En conclusión y vista la distribución de los bioindicadores más significativos podemos hacer las siguientes hipótesis biogeográfica de la Península Ibérica (Fig 7):

a) Los pisos bioclimáticos descendieron del orden de $1000 \mathrm{~m}$ de altitud.

b) Las condiciones climáticas actuales de la montaña mediterránea bajarían a nivel del mar y con ellas, sus habitantes.

c) La zona más cálida de Europa sería el sur de Iberia, es decir, la costa andaluza, como en la actualidad.

d) Las zonas más áridas serían el valle del Ebro y el SE peninsular, también como en la actualidad. e) El paralelo $40^{\circ}$ Norte es un buen límite para situar al sur las zonas más cálidas de Europa y al norte las más frías.

f) Predominio de los paisajes abiertos en todas las regiones con diversidad de plantas leñosas: fabáceas, lamiáceas, jaras, etc.

g) Los piñones fueron recolectados y consumidos sistemáticamente por los grupos solutrenses de la Cueva de Nerja y, probablemente, por los de Gibraltar.

\section{AGRADECIMIENTOS}

Este trabajo se ha financiado en parte por los proyectos: FFI2008-01200/FISO; HAR2008/03005 (Ministerio de Ciencia e Innovación, España); 05801/ARQ/07 (Seneca Foundation, Murcia); CGL2009-06988 (Ministerio de Ciencia e Innovación, España) y GV/2011/020 (Conselleria d'Educació, Generalitat Valenciana); CGL2011-12909-E; HAR2011-24878 (MCNN - Ministerio de Ciencia e Innovación) CGL2012-34717 (Ministerio de Economía y Competitividad).

\section{BIBLIOGRAFÍA}

Almeida, F.; Brugal, J. P.; Zilhão, J. y Plisson, H. 2007: "An upper Paleolithic Pompeii: Technology subsistence and Paleoethnography at Lapa do Anecrial". En N. Bicho (ed.): From the Mediterranean basin to the Portuguese Atlantic shore : papers in honor of Anthony Mark: actas do IV Congresso de Arqueologia Peninsular. Universidad do Algarve.

Aubry, T.; Brugal, J.-P.; Chauvière, F. X.; Figueiral, I.; Moura, M. H. y PlisSON, H. 2001: "Modalités d'occupation au Paléolithique supérieur dans la grotte de Buraca Escura (Redinha, Pombal, Portugal)". Revista Portuguesa de Arqueologia 4 (2): 19-46.

Aubry, T.; Dimuccio, L. A.; AlmeidA, M.; Neves, M. J.; Angelucci D. E. y CUNHA, L. 2011: "Palaeoenvironmental forcing during the MiddleUpper Palaeolithic transition in central-western Portugal". Quaternary Research 75: 66-79.

Aubry, T. ; Moura, M. y Fontugne, M. 1997 : "Les occupations de la grotte de Buraca Grande dépuis le Paléolithique supérieur et les apports de la séquence holocène à l'étude de la transition mésolithique/néolithique au Portugal". Bulletin de la Société préhistorique française 94 (2):182-190.

Aura, J. E.; JordÁ, J.; Pérez Ripoll, M.; Badal, E.; Morales, J. V. y AveZUELA, B. 2010: "25 años de investigación sobre el Paleolítico superior de Andalucia: la cueva de Nerja, Málaga (1979/2009)". En X. Mangano (ed.): El Paleolítico superior peninsular. Novedades del siglo XXI. Monografies SERP 8. Universitat de Barcelona. Barcelona: 149-172.

BADAL, E. 1990: Aportaciones de la antracología al estudio del paisaje vegetal y su evolución en el Cuaternario reciente, en la costa mediterránea del País Valenciano y Andalucía (18000-3000B.P). Ph.D. Thesis. Universitat de Valencia.

- 1998: "El interés económico del pino piñonero para los habitantes de la Cueva de Nerja". En J. L. Sanchidrian, J. L y M. D. Simón, M. D. (eds): Las culturas del Pleistoceno superior en Andalucía: 287-300.
- 2001: "La recolección de piñas durante la prehistoria en la Cueva de Nerja (Málaga)". En V. Villaverde (ed.): De Neandertales a cromañones. El inicio del poblamiento humano en las tierras valencianas. Universitat de València. Valencia: 101-104.

- 2006: "Carbones y cenizas, ¿qué nos cuentan del pasado?". En J. S. Carrión, S. Fernandéz y N. Fuentes (coord.): Paleoambientes y cambio climático. Fundación Séneca, Agencia de Ciencia y Tecnología de la Régión de Murcia. Murcia: 103-116.

- 2008: "El combustible y el paisaje vegetal". En J. V. Picazo y J. M. Rodanés (eds.): Los poblados del Bronce Final y Primera Edad del Hierro. Cabezo de la Cruz. La Muela, Zaragoza. Gobierno de Aragón. Zaragoza: 132-155.

BADAL, E. y CARRIÓN, Y. 2001: "Del Glaciar al Interglaciar: los paisajes vegetales a partir de los restos carbonizados hallados en las cuevas de Alicante". En V. Villaverde (ed.): De Neandertales a cromañones. El inicio del poblamiento humano en las tierras valencianas. Universitat de València. Valencia: 21-41.

Badal, E.; Villaverde, V. y Zilhão, J. 2012: "Middle Palaeolithie wood charcoal from thee sites in south and west lberia: Biogeographi implications". En E. Badal et al. (coord.): Wood and charcoal. Evidence for human and natural history. Sagvntvm Extra-13. Valencia: 13-24.

Banks, W. E.; Zilhão, J.; D'errico, F.; Kageyama, M.; Sima, A. y Ronchitelli, A. 2009: "Investigating links between ecology and bifacial tool types in Western Europe during the Last Glacial Maximum". Journal of Archaeological Science 36: 2853-2867.

Blasco, M. F. y RodanÉs, J. M. 2009: "Las fases de ocupación de la cueva del Gato 2 (Épila, Zaragoza)". Saldvie 9: 331-334.

Canals, A.; Rodríguez-Hidalgo, A.; Peña, L.; Mancha, E.; García-Díez, M.; Bañuls, S.; Euba, I.; López-García, J. M.; Barreno, N.; Bermejo, L.; GarCía, F. J.; Mejias, D.; Modesto, M.; Mordillo, A.; Aranda, V. y CarBONELL, E. 2010: "Nuevas aportaciones al Paleolítico superior del suroeste peninsular: la cueva de Maltravieso, más allá del santuario extremeño de las manos". En X. Mangano (ed.): El Paleolítico 
superior peninsular. Novedades del siglo XXI. Monografies SERP 8. Universitat de Barcelona. Barcelona: 137-148.

Carrión, J. S.; Finlayson, C.; Férnández, S.; Finlayson, G.; Allué, E.; LópezSáez, J. A.; López- García, P.; Gil-Romera, G.; Bailey, G. y GonzÁlezSAMPÉRIZ, P. 2008: "A coastal reser- voir of biodiversity for Upper Pleistocene human populations: Palaeoecological investigations in Gorham's Cave (Gibraltar) in the context of the Iberian Peninsula". Quaternary Sciences Reviews 27: 2118-2135.

Carrión, Y.; Ntinou, M. y BADAL, E. 2010: "Olea europaea L. in the North Mediterranean basin during the Pleniglacial and the Early-Middle Holocene". Quaternary Science Reviews 29: 952-968.

CHABAL, L. 1997: Forets et sociétés en Languedoc (Néolithique final, Antiquité tardive): I'anthracologie, méthode et paléoécologie. Editions de la Maison des Sciences de l'Homme. Paris.

Figueiral, I. y Carcalllet, C. 2005: "A review of Late Pleitocene and Holocene biogeography of highland Mediterranean pines (Pinus type sylvestris) in Portugal, based on wood charcoal". Quaternary Science Reviews 24: 2466-2476.

FIGUEIRAL, I. y TERRAL, J.-F. 2002: "Late Quaternary refugia of Mediterranean taxa in Portuguese Extremadura: Charcoal based palaeovegetation and climatic reconstruction". Quaternary Science Reviews 21: 549-558.

Frenzel, B.; Pécsi, M. y VelinchKo A. A. 1992: Atlas of paleoclimates and paleoenvironments of the northern hemisphere. Late Pleistocene Holocene. Geographical Research Institute, Hungarian Academy of Sciences y Gustav Fischer Verlag, Budapest, Stuttgart.

González-Sampériz, P.; Leroy, S.; CARrión, J. S.; Garcia-Antón, M.; GILGarcia, M. J. y FIgUeIRAL, I. 2010: "Steppes, savannahs and botanic gardens during the Pleistocene". Review of Palaeobotany and Palynology Special 162: 427-457.

Granja, H. M. y Carvalho, G. S. 1995: "As dataçòes pelo radiocarbono e o Plistocénico - Holocénico da zona costeira do NO de Portugal (Síntese de conhecimentos)". $3^{\circ}$ Reunião do Quaternário Ibérico. Actas. Universidade de Coimbra: 383-393.

JORDÁ, J. F. y AURA TORTOSA, J. E. 2006: "Radiocarbono, cronoestratigrafía y episodios ocupacionales en el Pleistoceno superior y Holoceno de la Cueva de Nerja (Málaga, Andalucia, España)". Zona Arqueológica, 7, Miscelánea en Homenaje a Victoria Cabrera 1: 579-595.

- 2008: "70 fechas para una cueva. Revisión crítica de 70 dataciones $\mathrm{C} 14$ del Pleistoceno superior y Holoceno de la Cueva de Nerja (Málaga, Andalucia, España)". Espacio, Tiempo y Forma. Serie I. Nueva Época, Prehistoria y Arqueología 1: 239-256.

LOWE, J. J. y WALKER, M. J. C. 1997: Reconstructing Quaternary Environments. Longman. London.

Lucena, A.; Martinez, S.; Angelucci, D.; Badal, E.; Villaverde, V.; Zapata, J. y ZILHÃO, J. EN PRENSA: "La ocupación solutrense del abrigo de la Boja (Mula, Murcia, España)". Espacio, Tiempo y Forma. Presente volumen.

Metcalfe, C. R. 1958: "Gorham' Cave: Report on the plant remains". Bull. Inst. of Archaeology 4: 219.

NiınOU, M. 2002: La paleovegetación en el norte de Grecia desde el Tardiglaciar hasta el Atlántico. Formaciones vegetales, Recursos y Usos. BAR International Series 1038.

OzENDA, P. 1975: "Sur les étages de végélation dans les montagnes du bassin méditerranéen". Doc. Cartographie Ecol. 16: 1-32.

Queiroz, P. F.; Mateus, J. E. y LeeuwaARden, W. V. 2002: "The paleovegetation context". En J. Zilhão y E. Trinkaus (eds.): Portrait of the Artist as a Child: The Gravettian Human Skeleton from the Abrigo do Lagar Velho. IPA, Trabalhos de Arqueologia 22. Lisboa: 92-111.

RAMIL, P. 1993: "Evolución climática e historia de la vegetación durante el Pleistoceno superior y el Holoceno en las regiones montañosas del noreste ibérico". En A. Pérez Alberti, L. Guitián Rivera y P. Ramil (eds.): La evolución del paisaje en las montañas del entorno de los caminos Jacobeo. Xunta de Galicia. Santiago de Compostela: 25-60.
RIVAS-Martinez, S. 1983: Pisos bioclimáticos de España. Lazaroa 5: 33-43. Rodriguez-ARIZA, 0. 2005: "Análisis antracológico del yacimiento solutrense de la Cueva de Ambrosio (Vélez Blanco, Almeria)". En J.L. Sanchidrián, A.M. Márquez y J.M. Fullola (eds.): La cuenca Mediterránea durante el Paleolítico superior, 38.000-10.000 año : IV Simposio de Prehistoria Cueva de Nerja: 226-233.

Ros Mora, M. T. 1985: Contribució antracoanalitica a l'estudi de l'entorn vegetal de l'Home, del Paleolític superior a l'Edat del Ferro a Catalunya. Tesis de Llicenciatura. Universitat Autonoma de Barcelona.

Rubiales, J. M.; Garcia-Amorena, I.; HernÁndez, L.; Génova, M.; Martinez, F.; Gómez-MANZANeque, F. y MorLA, C. 2010: "Late Quaternary dynamics of pinewoods in the Iberian Mountains". Review of Palaeobotany and Palynology 162: 476-491.

SCHWEIngRUBer, F. 1990: Anatomy of European woods. WSL/FNP, Paul Haupt Bern and Stuttgart Publishers.

UzoUIANO, P. 1992A: Recherches anthracologiques dans le secteur pyreneo-cantabrique (Pays Basque, Cantabria et Asturias): environnements et relations homme-milieu au Pleistocene superieur et début de l'Holocene. 1992. Tesis Doctoral. Université Montpellier II.

- 1992B: "L'homme et le bois au Paléolithique en région Cantabrique, Espagne. Examples d'Altamira et d'El Buxu". En J. L. Vernet (ed.): Les charbons de bois les anciens écosystèmes et le de l'homme. Bull. Société Botanique de France 139, Actualités botaniques (2/3/4): 361-372.

- 2009: "Análisis antracológico de la cueva de Cobrante. Paisaje vegetal, movilidad y gestión de los resursos leñosos en un medio cambiante". Sautuola XV: 63-73.

Valladas, H.; Cachier, H.; Arnold, M. Clotes, J.; Bernaldo De Quirós GuiDOTI, F.; CABReRA, V. y Uzouiano, P. 1992: "Direct radiocarbone dates for the prehistoric paintings at the Altamira, El Castillo and Niaux caves". Nature 357: 68-70.

Vernet, J. L.; Bazile-Robert, E. y Evin, J. 1979: "Conditions des analyses anthracologiques et des datation absolues sur des charbons de bois". Bulletin de la Societé Préhistorique de France 76: 76-79.

VILLAVERDE, V. 2001: Cova de les Cendres (Teulada - Moraira, Alicante). En V. Villaverde (ed.): De Neandertales a cromañones. El inicio del poblamiento humano en las tierras valencianas. Universitat de València: 411-414.

Villaverde, V.; Román, D.; Martínez-Valle, R.; Badal, E.; Bergadá, M. M.; Guillem, P. M.; PÉrez-Ripoll, M. y ToRmo, C. 2010: "El Paleolítico superior en el Pais Valenciano: novedades y perspectivas". En X. Mangano (ed.): El Paleolítico superior peninsular. Novedades del siglo XXI. Monografies SERP 8. Universitat de Barcelona. BarceIona: 85-113.

WiLLIS, K. J. y VAN ANDEL, T. H. 2004: "Trees or no trees? The environments of central and eastern Europe during the Last Glaciation". Quaternary Science Reviews 23: 2369-2387.

ZıเнÃo, J., 1997: O Paleolítico superior da Estremadura portuguesa, 2 vols, Ed. Colibri. Lisboa.

Zllhão, J.; Angeluccl, D. E.; Badal, E.; Lucena, A.; Martín, I; Martinez, S.; VILLAVERDE, V. y ZaPATA, J. 2010A: "Dos abrigos del Paleolítico superior en Rambla Perea (Mula, Murcia)". En X. Mangano (ed.): El Paleolítico superior peninsular. Novedades del siglo XXI. Monografies SERP 8. Universitat de Barcelona. Barcelona: 137-148.

Zilhäo, J.; Angeluccl, D. E.; Badal-García, E.; D'errico, F.; Daniel, F.; Dayet, L.; Douka, K.; Higham, T. F. G.; Martínez-SÁnchez, M. J.; MontesBernárdez, R.; Murcia-Mascarós, S.; Pérez-Sirvent, C.; Roldán-García, C.; Vanhaeren, M.; Villaverde, V.; Wood, R. y Zapata, J. 2010 b: "Symbolic use of marine shells and mineral pigments by lberian Neandertals". Proc. Natl. Acad. Sci. USA 107:1023-1028.

ZILHÃO, J. y TRINKAUS, E., 2002: Portrait of the Artist as a Child: The Gravettian Human Skeleton from the Abrigo do Lagar Velho. IPA, Trabalhos de Arqueologia 22. Lisboa. 